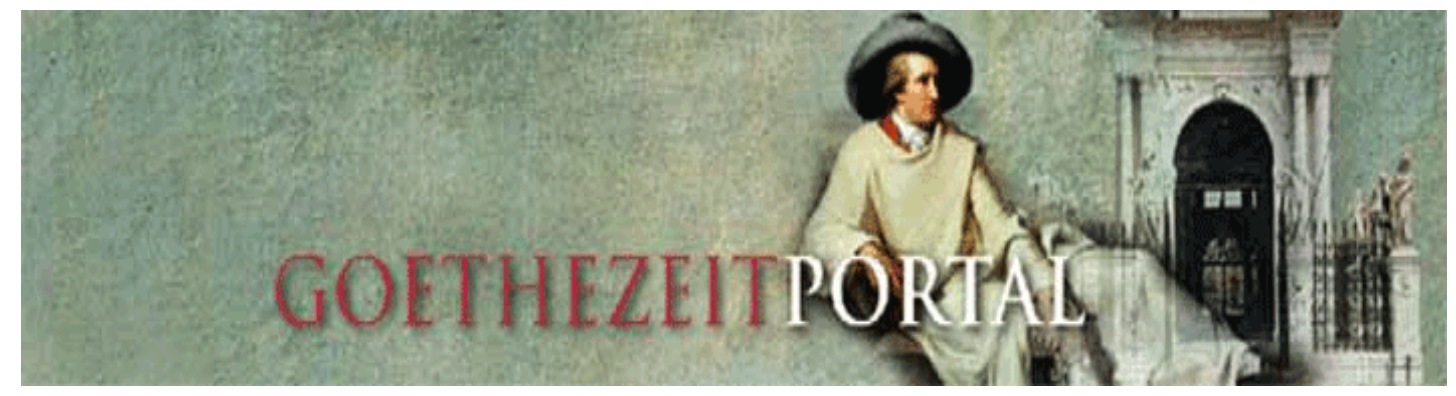

CLAUDIA STOCKINGER

\title{
Dramaturgie der Zerstreuung. Schiller und das romantische Drama
}

\begin{abstract}
Vorblatt
Publikation

- Vortrag „Dramaturgie der Zerstreuung. Schiller und das romantische Drama“, gehalten auf einer Tagung zum Drama der Romantik, 13.-15. September 1999, an der Universität Karlsruhe;

- die überarbeitete Fassung erstmalig abgedruckt unter gleichnamigem Titel im Sammelband zur Tagung:

Claudia Stockinger: Dramaturgie der Zerstreuung. Schiller und das romantische Drama. In: Das romantische Drama. Produktive Synthese zwischen Tradition und Innovation, hg. von Uwe Japp, Stefan Scherer und Claudia Stockinger, Tübingen: Niemeyer, 2000, S. 199-225.

- Neupublikation im Goethezeitportal

- Vorlage: Datei der Autorin

URL: 〈http://www.goethezeitportal.de/db/wiss/schiller/stockinger_dramaturgie.pdf> Eingestellt am 27.08.2005.
\end{abstract}

\section{Autorin}

Prof. Dr. Claudia Stockinger

Georg-August-Universität Göttingen

Seminar für deutsche Philologie

Käte-Hamburger-Weg 3

37073 Göttingen

Emailadresse: <claudia.stockinger@phil.uni-goettingen.de>

\section{Empfohlene Zitierweise}

Beim Zitieren empfehlen wir hinter den Titel das Datum der Einstellung oder des letzten Updates und nach der URL-Angabe das Datum Ihres letzten Besuchs dieser Online-Adresse anzugeben: Claudia Stockinger: Dramaturgie der Zerstreuung. Schiller und das romantische Drama (27.08.2004). In: Goethezeitportal. URL: <http://www.goethezeitportal.de/db/wiss/schiller/stockinger_dramaturgie.pdf> (Datum Ihres letzten Besuches). 


\title{
CLAUDIA STOCKINGER
}

\section{Dramaturgie der Zerstreuung. Schiller und das romantische Drama}

\author{
Inhalt
}

I. „Jeder Stoff will seine eigene Form“. Schillers Experimentaldramatik. II. „Mit meinem Blick wollt ich die Schlacht regieren!“. Die hermeneutischen Herausforderungen der Braut von Messina und der Jungfrau von Orleans. - III. „Es mangelt ihm die Einheit der Handlung“. Panoramatik in Wilhelm Tell

\section{I „Jeder Stoff will seine eigene Form“. Schillers Experimentaldramatik}

Aus der Perspektive einer Geschichte der Streitkultur ist die literaturpolitische Situation der späten 1790er Jahre von einer grundlegenden Opposition bestimmt. Demzufolge läßt sich diese Situation als epochale Gleichzeitigkeit, als Nebeneinander von 'Weimarer Klassik' und 'Jenaer (Früh-) Romantik' beschreiben. ${ }^{1}$ Das Ende einer produktiven Zusammenarbeit zwischen Schiller und vor allem Friedrich Schlegel nach 1796 konstituiert Parteien, ${ }^{2}$ die jede Übereinkunft verweigern (beispielsweise wird auf beiden Seiten ausgiebig übereinander 'gelacht') und deren hauptsächlich polemische Selbstverständigung und Programmatik schließlich von einer auf kategoriale Vereinfachungen angewiesenen Literaturgeschichtsschreibung kanonisiert wird. Nur wenige Jahre nach Schillers Tod jedenfalls fällt das Urteil über den ehemaligen Gegner sehr viel gelassener aus: Friedrich Schlegel nennt Schiller in seinen Wiener Vorlesungen von 1812 den „wahre[n] Begründer unsrer Bühne“, ${ }^{3}$ Tiecks Rezension des Wallenstein (1823) würdigt die prototypische Qualität von Schillers historischer Dramatik, ${ }^{4}$ und Brentano rechnet 1814 das ehemals ,erbärmliche Machwerk“"5 Die Braut von Messina der „modernen romantischen Kunst“" zu. Der späte Goethe

\footnotetext{
1 „Schiller ist der umbrandete Fels, gegen den die Wogen der Romantik anprallen. Er wird der Anlaß, vielleicht aber auch die Ursache der Spaltung der deutschen Bewegung in Klassik und Romantik“ (Schiller und die Romantiker. Briefe und Dokumente, hg. und eingeleitet von Hans Heinrich Borcherdt, Stuttgart 1948, S. 144).

2 Schiller und die Romantiker (wie Anm. 1), S. 35-61.

${ }^{3}$ Friedrich Schlegel: Kritische Ausgabe, hg. von Ernst Behler unter Mitwirkung von Jean-Jacques Anstett und Hans Eichner. Sechster Band: Geschichte der alten und neuen Literatur, MünchenPaderborn-Wien-Zürich 1961, S. 404. - Diese Ausgabe wird im folgenden unter Verwendung der Sigle KA und anschließender Band- / Seitenangabe zitiert.

4 Ludwig Tieck: Die Piccolomini. Wallenstein's Tod. In: ders.: Kritische Schriften. Zum ersten Male gesammelt und mit einer Vorrede herausgegeben. Dritter Band (Dramaturgische Blätter. Erster Theil), Leipzig 1852 (Repr. Berlin-New York 1974), S. 37-62; S. 40.

5 Achim von Arnim und Clemens Brentano. Bearbeitet von Reinhold Steig (Achim von Arnim und die ihm nahe standen, hg. v. R. S. und Herman Grimm. Erster Band), Stuttgart 1894, S. 97.

6 Schiller - Zeitgenosse aller Epochen. Dokumente zur Wirkungsgeschichte Schillers in Deutschland, Teil I: 1782-1859, hg., eingeleitet und kommentiert von Norbert Oellers, Frankfurt/M. 1970, S. 149.
} 
wiederum vereinseitigt die literaturpolitische Polarisierung Deutschlands um 1800 auf seine eigene Auseinandersetzung mit Schiller:

Der Begriff von klassischer und romantischer Poesie, der jetzt über die ganze Welt geht und so viel Streit und Spaltungen verursacht [...], ist ursprünglich von mir und Schiller ausgegangen. [...] [Schiller] bewies mir, daß ich selber, wider Willen, romantisch sei, und meine Iphigenie, durch das Vorwalten der Empfindung, keineswegs so klassisch und im antiken Sinne sei, als man vielleicht glauben möchte. Die Schlegel ergriffen die Idee und trieben sie weiter $[\ldots]]^{7}$

Was sich an dieser Bemerkung u. a. auch ablesen läßt, ist Schillers Reserve gegenüber dem 'Romantischen', und tatsächlich bezeichnet 'Klassizität' seit Ende der 1780er Jahre die Schillers poetologisches Programm und ästhetisches Urteil regulierende Idee. ${ }^{8}$ Aus der historischen Situation der funktionalen Ausdifferenzierung der Gesellschaft, die Schiller in Begriffe wie 'Zerstückelung', 'Vereinzelung' oder 'Fragmentierung' faßt, ergibt sich auch für die Kunst eine erweiterte Funktionsbeschreibung, die auf die Wiederherstellung der verlorenen Einheit auf höherer Ebene zielt. ${ }^{9}$ Die anthropologische Voraussetzung für dieses synthetisierende Potential der Kunst ist der "Spieltrieb“, der „die Zeit in der Zeit aufzuheben“ vermag (NA 20, 353). 'Einheit' läßt sich demnach gerade in der Fiktion herstellen, ${ }^{10}$ und innerhalb dieses Bereichs hat das Drama dafür die geeigneten Mittel. Zumindest kann die in Ueber die ästhetische Erziehung des Menschen formulierte Synthese von 'sinnlichem Trieb' und 'Formtrieb' auf diese generische Zuordnung hin transparent gemacht werden, wenn hier die ,lebende Gestalt“ als „Gegenstand des Spieltriebes“ (NA 20, 355) figuriert und „das Gemüth“ sich nur dann der formalen „Abstraktion“ gewachsen zeigt, ,sobald die unmittelbare Anschauung sie begleiten kann“ (NA 20, 357). ${ }^{11}$ Poetische Darstellung heißt dabei Ausbildung der Form, die den Menschen in

\footnotetext{
${ }^{7}$ Johann Peter Eckermann: Gespräche mit Goethe in den letzten Jahren seines Lebens, hg. von Heinz Schlaffer (Johann Wolfgang Goethe: Sämtliche Werke nach Epochen seines Schaffens. Münchner Ausgabe, hg. von Karl Richter. Band 19, München-Wien 1986), S. 367 (21. März 1830).

${ }^{8}$ Zum Beispiel [Friedrich Schiller]: Über Bürgers Gedichte. In: Schillers Werke. Nationalausgabe. Zweiundzwanzigster Band, hg. von Herbert Meyer, Weimar 1958, S. 245-264, S. 259. - Diese Ausgabe wird im folgenden unter Verwendung der Sigle NA und anschließender Band- / Seitenangabe zitiert.

9 NA 20, 322 (Ueber die ästhetische Erziehung des Menschen in einer Reihe von Briefen), oder NA 22, 245 (Über Bürgers Gedichte): „,Bei der Vereinzelung und getrennten Wirksamkeit unsrer Geisteskräfte, die der erweiterte Kreis des Wissens und die Absonderung der Berufsgeschäfte notwendig macht, ist es die Dichtkunst beinahe allein, welche Kopf und Herz, Scharfsinn und Witz, Vernunft und Einbildungskraft in harmonischem Bunde beschäftigt, welche gleichsam den ganzen Menschen in uns wieder herstellt".

${ }^{10}$ Darin weicht Schillers Spiel-Vorstellung von der frühromantischen Universalisierung des Begriffs ab (vgl. Winfried Menninghaus: Unendliche Verdopplung. Die frühromantische Grundlegung der Kunsttheorie im Begriff absoluter Selbstreflexion, Frankfurt/M. 1987, S. 149).

${ }^{11}$ Epos und Drama unterscheiden sich Schiller (und Goethe) zufolge hauptsächlich darin, daß „der Epiker die Begebenheit als vollkommen vergangen vorträgt, und der Dramatiker sie als vollkommen gegenwärtig darstellt“" (NA 21, 57; [Johann Wolfgang Goethe/Friedrich Schiller]: Ueber epische und dramatische Dichtung). Vgl. Georg Wilhelm Friedrich Hegel: Vorlesungen über die Aesthetik. Dritter Band. Mit einem Vorwort von Heinrich Gustav Hotho. Dritte Auflage, Stuttgart 1954 (ders.: Sämtliche Werke. Jubiläumsausgabe in zwanzig Bänden, hg. von Hermann Glockner. Vierzehnter Band), S. 479.
} 
jene ästhetische Reflexion entläßt, vermittels derer die Kunst an ihr eigentliches Ziel, die „hohe Gleichmüthigkeit und Freyheit des Geistes“, gelangt (NA 20, 380).

Das ästhetisch so begründete 'Klassische' wird in den 1820er Jahren von Wilhelm von Humboldt festgeschrieben, dem gleichsam ersten Historiographen der 'Weimarer Klassik', ${ }^{12}$ die formalen Anforderungen an das klassische Drama finden sich (in etwa zeitgleich) in Hegels Vorlesungen über die Aesthetik. In dezidierter Abgrenzung Schillers von Tieck und den „Herrn Schlegel's“"13 und von einer ,moderne[n] Poesie“, die, ,insoweit sie im romantischen Typus dichtet“, „im Aeußerlichen bunter und willkürlicher seyn darf“", ${ }^{14}$ reformuliert Hegel Schillers Überlegungen zur tragischen Kunst, die auf Unmittelbarkeit, auf Ähnlichkeit (mit der Wirklichkeit), auf Vollständigkeit und Geschlossenheit sowie (als Konsequenz der Ausrichtung auf das Publikum) auf Dauer zielen. ${ }^{15}$ Dabei gehen die in Ueber die tragische Kunst behaupteten Vorteile der Tragödie für den höchsten Zweck der Kunst überhaupt (NA 20, 153), die Evokation von Vergnügen und damit der 'Vorstellung moralischer Zweckmäßigkeit' ${ }^{16}$ in diese Überlegungen ein. Für das illudierende Potential des Dramas entscheidend ist das Kriterium der Aufführbarkeit; ${ }^{17}$ zerstreuende Momente wie Shakespeares 'episierende' Verständnishilfen bleiben ausgeschlossen. ${ }^{18}$

Dieser hier nur skizzierte Katalog gibt einen bis heute gültigen Rahmen für die Beschreibung, Klassifizierung und Bewertung dramatischer Produktion vor, der eine bemerkenswerte Kontinuität begründet, von der zeitgenössischen Kritik (die sowohl Maria Stuart als auch Wilhelm Tell nach dem Kriterium der Geschlossenheit beurteilt) ${ }^{19}$ bis zur aktuellen Schiller-Forschung. ${ }^{20}$ Der Blick auf die Theorie verstellt den

${ }^{12}$ Wilhelm von Humboldt: Ueber Schiller und den Gang seiner Geistesentwicklung (1830). - Rezension von Goethes Zweitem römischen Aufenthalt. In: ders.: Gesammelte Schriften, hg. von der Königlich Preußischen Akademie der Wissenschaften. Abteilung I: Werke, hg. von Albert Leitzmann. Sechster Band. 1827-1835. Zweite Hälfte, Berlin 1907 (Repr. Berlin 1968), S. 492-527; S. 528-550. Vgl. dazu auch ders.: Über Schiller und Goethe. Aus den Briefen und Werken. Gesammelt und erläutert von Eberhard Haufe, Weimar 1963, S. 23-148.

13 Hegel: Vorlesungen über die Aesthetik. Dritter Band (wie Anm. 11), S. 502.

14 Hegel: Vorlesungen über die Aesthetik. Dritter Band (wie Anm. 11), S. 488; der 'spätere' Schiller dagegen hatte ,das Princip der antiken Tragödie auch in der modernen dramatischen Kunst wieder herzustellen im Sinne“ (S. 566). Zu Hegels Differenzierung in romantische Kunstform / Moderne (deren digredierende Tendenzen in der Form er anerkennt) und romantische Schule / aktuelle Romantik (deren digredierende Tendenzen er ablehnt) vgl. Karl Heinz Bohrer: Die Kritik der Romantik. Der Verdacht der Philosophie gegen die literarische Moderne, Frankfurt/M. 1989, S. 174-181.

${ }^{15}$ Hegel: Vorlesungen über die Aesthetik. Dritter Band (wie Anm. 11), v. a. S. 479-525.

16 NA 20, 147 (Ueber den Grund des Vergnügens an tragischen Gegenständen).

17 Im Gegensatz zum Epos (NA 21, 59; Ueber epische und dramatische Dichtung); Hegel: Vorlesungen über die Aesthetik. Dritter Band (wie Anm. 11), S. 488, 512-525.

${ }^{18}$ Hegel: Vorlesungen über die Aesthetik. Dritter Band (wie Anm. 11), S. 489.

19 Wird Maria Stuart ,eine sehr große Einheit der Handlung“ konzediert (Schiller im Urtheile seiner Zeitgenossen. Zeitungskritiken, Berichte und Notizen, Schiller und seine Werke betreffend, aus den Jahren 1801-1805, gesammelt und hg. von Julius W. Braun [Schiller und Göthe im Urtheile ihrer Zeitgenossen, 1. Abtheilung. Dritter Band], Berlin 1882, S. 122 [Merkel, Briefe an ein Frauenzimmer]), so genügt Wilhelm Tell diesen Anforderungen gerade nicht. Dazu ausführlicher der dritte Abschnitt des vorliegenden Aufsatzes.

${ }^{20}$ Im Bereich der Dramentheorie z. B. Klaus L. Berghahn: „Das Pathetischerhabene“. Schillers Dramentheorie. In: Deutsche Dramentheorien I. Beiträge zu einer historischen Poetik des Dramas in Deutschland, hg. von Reinhold Grimm, 3., verbesserte Auflage, Wiesbaden 1980, S. 197-221, v. a. S. 208-215. 
Blick auf das Neue der Dramaturgie Schillers, die den vielfältig bemerkten Ordnungsverlust in die dramatische Darstellung hineinnimmt und dabei Formen generiert, die Grenzziehungen zu im Umkreis der Romantik zeitgleich entstehenden Dramen $^{21}$ mindestens erschweren; zu denken ist hier u. a. an die episierenden Tendenzen des Wallenstein oder die opernhaften der Jungfrau von Orleans, an die 'desillusionierende' metrische Versatilität der Braut von Messina oder die strukturelle Panoramatik des Wilhelm Tell. Die Auflösung der klassischen Finalstruktur in der episodischen Reihung, die den kausalen Verlauf durch ein szenisch organisiertes Mosaik substituiert und den sich partiell verselbständigenden dramatischen Text ins Episodische ausdehnt, bezeichnet ein von beiden Seiten dramaturgisch eingelöstes Zugeständnis an eine veränderte Vorstellung von 'Ganzheit' oder 'Totalität', das auf die panoramatische Kompetenz der Zuschauer / Leser setzt. ${ }^{22}$ Die ästhetische Integration der Teile legt eine im Wortsinn 'erhabene' Position des Betrachters zugrunde, der sich einen (wenngleich auktorial gesteuerten) Überblick über die Zusammenhänge verschaffen und sich so, wie der Besucher eines Panoramas, in der dramatischen Handlung bewegen muß, die ,gleichsam stille zu stehen“ scheint. ${ }^{23}$ Schillers Lektüreregeln für das Epos gelten m. E. ebenso für eine Dramatik, deren neuartige Disposition den unmittelbaren Rezeptionszeugnissen zufolge für einige Irritation gesorgt und zu einem Vergleich mit dem 'romantischen Drama' herausgefordert hat. Immerhin reagiert die zeitgenössische Öffentlichkeit sensibel auf die strukturelle Ähnlichkeit der dramatischen Produktionen, wenn (um zwei Beispiele zu nennen) Schillers Braut von Messina als eine Wiederauflage von Schlegels Alarcos gelesen ${ }^{24}$ oder Die Jungfrau von Orleans in programmatische Nähe zur 'Schlegel-Schule' gerückt wird. ${ }^{25}$ Hegel wiederum räumt ein, daß Schiller zeitweilig, zum Beispiel bei der Jungfrau von Orleans, auf 'Abwege' - in diesem Fall der Oper - geraten sei. ${ }^{26}$ Und neuere Studien erklären die beobachtete Inkompatibilität von Poetologie und Dramaturgie kurzerhand zu Schillers klassischem Programm, wenn etwa die formale Heterogenität von Wilhelm Tell als ein (in dieser Hinsicht wohl gescheiterter?) „Versuch“ Schillers bezeichnet wird, „das Modell 'Weimarer Klassik' publikumsfähig zu machen". ${ }^{27}$

${ }^{21}$ Gerhard Schulz: Die deutsche Literatur zwischen Französischer Revolution und Restauration 17891830. Erster Teil: Das Zeitalter der Französischen Revolution. 1789-1806, München 1983, S. 449570. Zweiter Teil: Das Zeitalter der napoleonischen Kriege und der Restauration. 1806-1830, München 1989, S. 558-679.

${ }^{22}$ Vgl. dazu ausführlich C. S.: Das dramatische Werk Friedrich de la Motte Fouqués. Ein Beitrag zur Geschichte des romantischen Dramas, phil. Diss. Karlsruhe 1999, v. a. Kap. 1 und 2 (Druck in Vorbereitung).

${ }^{23}$ Schiller an Goethe, am 26. Dezember 1797 (Der Briefwechsel zwischen Schiller und Goethe, hg. von Emil Staiger, Frankfurt/M. 1977, S. 524).

${ }^{24}$ So die (unabhängigen) Urteile von Brentano, Gentz oder Jacobi (vgl. KA 5, LXXXI).

25 Aus Anlaß der von Johann August Apel verfaßten ,,rasenden Potenzen-Recension der Jungfrau von Orleans“" schreibt L. F. Huber an Karl August Böttiger: „Sucht man etwa mit solchen Werken Versöhnung mit den Schlegels?“ (Schiller und sein Kreis in der Kritik ihrer Zeit, hg. von Oscar Fambach [Ein Jahrhundert deutscher Literaturkritik. Band II], Berlin 1957, S. 481).

${ }^{26}$ Hegel: Vorlesungen über die Aesthetik. Dritter Band (wie Anm. 11), S. 523.

${ }^{27}$ Friedrich Schiller: Dramen IV, hg. von Matthias Luserke (Werke und Briefe in zwölf Bänden), Frankfurt/M. 1996, S. 825f. - Auch Monika Ritzers aufschlußreiche Ausführungen über den 'drama- 
Die folgenden Überlegungen gehen von der generischen Vielfalt eines Werkkomplexes aus, über dessen Zuordnung zur 'klassischen Dramatik' Schillers Konsens besteht,$^{28}$ wobei das Hauptaugenmerk zum einen (in Zusammenhang mit dem Chor-Projekt der Braut von Messina) auf Die Jungfrau von Orleans (II) liegt, zum anderen auf Wilhelm Tell (III). Dafür ist die Dramaturgie der Texte Schillers von der sowohl die Literaturkritik als auch die Bühnenbearbeitungen leitenden Poetologie zu unterscheiden, und damit die Textpraxis von einer Dramentheorie, ${ }^{29}$ die durch die Autonomisierung der Form im dramaturgischen Experiment, durch die Aufhebung struktureller u. a. Vorgaben im ästhetischen Spiel subvertiert wird. In Material, Mitteln und Intention nähert sich Schillers Dramatik romantischer Universalpoesie. Grundsätzlich soll dabei nicht von Einflußnahme in die eine oder andere Richtung die Rede sein, sondern von Vergleichbarkeit: Schillers Plädoyer für strikte Gattungstrennung ${ }^{30}$ beispielsweise widerspricht dem integrativen Charakter der Dramen, die in je eigener Intensität epische und lyrische Elemente einbinden; die Forderung nach absoluter Illusion $^{31}$ schließt vermittelnde Instanzen (wie die Chorkommentare der Braut von Messina) oder die Auflösung einheitlicher Sinnzusammenhänge im poetischen Spiel (z. B. in die Vieldeutigkeiten der Jungfrau von Orleans) aus, wenngleich die (dramen-)praktische Anwendung der Theorie des Pathetisch-Erhabenen sich nur darüber realisieren läßt; ${ }^{32}$ die an thematischer und darum auch struktureller Kompaktheit interessierte Bühnenbearbeitung von Goethes Egmont läuft, wie es in einer zeitgenössischen Rezension heißt, in ein „romantisch-epische[s] Ausspinnen der Handlung“" aus. ${ }^{33}$ Daß eine idealisierende Verallgemeinerung - strukturell gesehen, die klassizistisch motivierte Verdichtung - aufgrund der zunehmenden Einsicht in die Komplexität der Weltverhältnisse kaum mehr gelingen kann, verdeutlichen die Ent-

tischen Stil' Schillers setzen die Vereinbarkeit von Theorie und dramatischer Praxis voraus (M. R.: Schillers dramatischer Stil. In: Schiller-Handbuch, hg. von Helmut Koopmann, Stuttgart 1998, S. 240-269).

${ }_{28}, \mathrm{Zu}$ Schillers klassischen Dramen zählen gemeinhin die Wallenstein-Trilogie von 1800 [...], Maria Stuart (1801), Die Jungfrau von Orleans (1801), Die Braut von Messina (1803), Wilhelm Tell (1804) und das Dramolett Die Huldigung der Künste (1805)““ (Matthias Luserke: Schillers klassische Dramen. In: Friedrich Schiller: Dramen IV [wie Anm. 27], S. 521-535; S. 521).

29 'Dramaturgie' bezeichnet im folgenden also die 'innere Logik' der Textorganisation, ohne einen Bezug zur Aufführung oder zur Aufführbarkeit des Dramas herzustellen (vgl. dagegen Theaterlexikon, hg. von Christoph Trilse, Klaus Hammer und Rolf Kabel, Berlin 1978, S. 137). Davon unterschieden wird zudem die Dramentheorie (dagegen Theaterlexikon. Begriffe und Epochen, Bühnen und Ensembles, hg. von Manfred Brauneck und Gérard Schneilin. 3., vollständig überarbeitete und erweiterte Neuausgabe, Reinbek bei Hamburg 1992, S. 285).

${ }^{30}$ Vgl. dazu Helmut Koopmann: Schriften von Schiller und Goethe. In: Schiller-Handbuch (wie Anm. 27), S. 639-652; S. 643f.

${ }^{31}$ NA 21, 59 (Ueber epische und dramatische Dichtung): „Der zuschauende Hörer muß von Rechtswegen in einer steten sinnlichen Anstrengung bleiben, er darf sich nicht zum Nachdenken erheben, er muß leidenschaftlich folgen, seine Phantasie ist ganz zum Schweigen gebracht, [...] und selbst was erzählt wird muß gleichsam darstellend vor die Augen gebracht werden“.

${ }^{32}$ Die emotionale Wirkung setzt auf Illusion, die rationale auf Vermittlung, vgl. NA 20, 195 (Vom Erhabenen).

33 Johann Wolfgang Goethe: Egmont. Erläuterungen und Dokumente, hg. von Hans Wagener, Stuttgart 1974, S. 90. - Wenn an dieser Stelle von 'epischer Verlängerung' die Rede ist, dann mag sich das auf die im Vergleich zur Vorlage stärkere Akzentuierung der Straßen- und Bürgerszenen beziehen. Allerdings ignoriert der Rezensent gerade die motivierende Funktion einer Zusammenführung dieser Szenen. 
stehungsgeschichten gerade der dramatischen Fragmente Schillers. Die Unwahrscheinlichkeit und Unübersehbarkeit etwa von Demetrius blockiert - Schillers eigenen Überlegungen zufolge - dessen Fertigstellung ${ }^{34}$ der allmähliche Verlust des 'punctum saliens' verhindert die weitere Bearbeitung der seit 1788 geplanten Malteser. ${ }^{35}$

Schillers Interesse für das Neue bezieht sich zunächst einmal auf die Ebene der Zeitgeschichte und Politik: „Zerfallen sehen wir in diesen Tagen / Die alte feste Form“ (NA 8, 5), heißt es im Prolog zu Wallensteins Lager. Diese an einem Ausschnitt des 30jährigen Krieges exemplifizierte zeitkritische Diagnose begründet aber zugleich sowohl das nationale Theaterprojekt Schillers (und der Romantiker) ${ }^{36}$ als auch die neuartige Disposition der darauf reflektierenden Dramatik, die jetzt ,,[n]icht raschen Schritts mit einem Mal ans Ziel“ gelangt, sondern ,den großen Gegenstand / In einer Reihe von Gemälden nur“ (NA 8,6) darzustellen vermag. Den später gegen das 'Simultandrama' Wallenstein ${ }^{37}$ erhobenen Vorwürfen der Ermüdung durch Dispersion $^{38}$ steuert Schillers Prolog damit von vornherein entgegen. In diesem Sinne bezeichnet der Terminus 'Zerstreuung' zweierlei: zum einen, bezogen auf die poetische Praxis, ein Modernitätssignal, das die dramaturgischen Konsequenzen der gerade von Schiller immer wieder benannten neuen Unübersichtlichkeit anzeigt, zum anderen, bezogen auf die Rezeption, eine Verlustkategorie, vermittels derer die vielfältigen Formen der Ablenkung des Publikumsinteresses auf einen Nenner gebracht werden. Schillers Simplizitätsideal ${ }^{39}$ schließt eine Dramaturgie der Zerstreuung aus (,'Ein Kunstwerk ist einfach, wenn es den Kunstliebhaber nicht durch Verschieden-

${ }^{34}$ „Gegen das Stück läßt sich anführen [...] 2 Daß es abentheuerlich u. unglaublich ist. [...] 4 Die Menge u. Zerstreuung der Personen schadet dem Intereße 5 Die Größe und der Umfang, daß es kaum zu übersehen. 6. Die Schwierigkeit es zu executieren auf den Theatern 7. Die Unregelmäßigkeit in Absicht auf Zeit und Ort [...]" (NA 11, 179 [Demetrius]).

35 Hatte Schiller am 22. Oktober 1799 (in einem Brief an Goethe) noch davon gesprochen, daß ,das punctum saliens [...] gefunden“" sei und daß, wenngleich der Stoff keine personelle Beschränkung erlaube, „die Mannigfaltigkeit [...] nicht zerstreuen und der Einfachheit des Ganzen keinen Abbruch tun“ werde (Der Briefwechsel zwischen Schiller und Goethe [wie Anm. 23], S. 819f.), so scheitert die Ausarbeitung letztendlich gerade an der zunehmenden Komplexität des Handlungszusammenhangs (und zwar nach Abschluß der Jungfrau): ,[...] noch fehlt mir das punctum saliens zu diesem Stück“ (an Körner, 13. Mai 1801; Briefwechsel zwischen Schiller und Körner, hg., ausgewählt und kommentiert von Klaus L. Berghahn, München 1973, S. 312).

${ }^{36}$ Demzufolge leiten sich Poetologie und Poesie um 1800 aus einem Gegensatz zur allgemeinen politischen und nationalen Lage her, vgl. Schiller an Süvern, 26. Juli 1800: „Unsre Tragödie wenn wir eine solche hätten, hat mit der Ohnmacht, der Schlaffheit, der Charakterlosigkeit des Zeitgeistes und mit einer gemeinen Denkart zu ringen, sie muß also Kraft und Charakter zeigen, sie muß das Gemüth zu erschüttern, zu erheben, aber nicht aufzulösen suchen“ (NA 30, 177); vgl. A. W. Schlegel an Fouqué, 12. März 1806: „Unsere Zeit krankt gerade an [...] Schlaffheit, Unbestimmtheit, Gleichgültigkeit, Zerstücklung des Lebens in kleinliche Zerstreuungen und an Unfähigkeit zu großen Bedürfnissen [...]. Wir bedürfen also einer [...] wachen, unmittelbaren, energischen und besonders einer patriotischen Poesie“ (A. W. S.: Sämmtliche Werke, hg. von Eduard Böcking. Achter Band [Vermischte und kritische Schriften. Zweiter Band: Charakteristiken und Litteratur], Leipzig 1846, S. 142-153; S. 145f.).

${ }^{37}$ Hartmut Reinhardt: Wallenstein. In: Schiller-Handbuch (wie Anm. 27), S. 395-414; S. 397.

38 So Johann Daniel Falk an Karl Morgenstern, November 1798 (Schiller und sein Kreis [wie Anm. 25], S. 432).

39 Zum Beispiel Schiller an Körner, 29. Dezember 1794; Briefwechsel zwischen Schiller und Körner (wie Anm. 35), S. 231. 
heit der Gegenstände zerstreuet'“) $)^{40}$, die experimentalpoetische Qualität der Dramatik aber hebt dieses Ideal auf:

Jeder Stoff will seine eigene Form, und die Kunst besteht darin, die ihm anpassende zu finden. Die Idee eines Trauerspiels muß immer beweglich und werdend sein, und nur virtualiter in hundert und tausend möglichen Formen sich darstellen. ${ }^{41}$

\section{II. „Mit meinem Blick wollt ich die Schlacht regieren!“. Die hermeneutischen Herausforderungen der Braut von Messina und der Jungfrau von Orleans}

Der Untertitel der Jungfrau von Orleans („Eine romantische Tragödie“) kündigt eine 'moderne' Bearbeitung an, die alles 'Antike' in Thematik und Darstellung ausblendet. Die Legende stellt zeitlich einen (topisch unbestimmten) mittelalterlichen Rahmen, ideologisch einen religiös konnotierten Begründungszusammenhang für die 'wunderbaren' Abläufe bereit. Mit anderen Worten inszeniert der Text über in die Figurenrede integrierte Ritterromantik, ${ }^{42}$ nationale Mythenbildung ${ }^{43}$ und deren christlich-naive Deutung ${ }^{44}$ eine geschlossene zweite Wirklichkeit, die das Interesse und die Aufmerksamkeit des Publikums von der historischen Realität der Ereignisse auf die poetische Wahrheit der Darstellung lenkt: „Das Historische ist überwunden und doch, soviel ich urteilen kann, in seinem möglichsten Umfang benutzt, die Motive sind alle poetisch und größtenteils von der naiven Gattung“. ${ }^{45}$ Diesem in einem Brief an Goethe skizzierten Poetisierungs-Projekt ist ferner der metrische Wechsel verpflichtet, der sowohl die Gleichförmigkeit klassischer Simplizität aufbricht als auch das kohärenzstiftende Potential parallelistischer Strukturen nutzt, ${ }^{46}$ das sich durch die

\footnotetext{
${ }^{40}$ Wörterbuch der Deutschen Sprache. Veranstaltet und hg. von Joachim Heinrich Campe. Fünfter und letzter Theil, Braunschweig 1811, S. 852.

41 An Körner, 28. Juli 1800; Briefwechsel zwischen Schiller und Körner (wie Anm. 35), S. 307 Ebenso an Goethe, 26. Juli 1800: „Man muß [...] es wagen, bei einem neuen Stoff die Form neu zu erfinden, und sich den Gattungsbegriff immer beweglich erhalten“ (Der Briefwechsel zwischen Schiller und Goethe [wie Anm. 23], S. 860). - Daß in den ,nach Wallenstein und vor Wilhelm Tell geschriebenen Bühnenstücken“ die „Fülle des geschichtlichen Geschehens mit seinen ausufernden Episoden und Wirbeln [...] zu einem Handlungsablauf von 'klassischer' Einfachheit und Prägnanz" 'gebändigt' werde (Karl S. Guthke: Maria Stuart. In: Schiller-Handbuch [wie Anm. 27], S. 415-441; S. 416), überrascht nicht nur in Hinsicht auf Die Jungfrau von Orleans.

${ }^{42}$ In der Rede Karls: „Er will die alten Zeiten wieder bringen, / Wo zarte Minne herrschte, wo die Liebe / Der Ritter große Heldenherzen hob, / Und edle Frauen zu Gerichte saßen, / Mit zartem Sinne alles Feine schlichtend“ (NA 9, 185).

${ }^{43}$ Das ist die Funktion der Beschreibung des 'Druidenbaums' (NA 9, 170).

44 'Heiligenbild' schlägt 'Druidenbaum', vgl. NA 9, 170f.; vor allem Johannas überlegener Auftritt am Hof des Königs (sie erkennt diesen, ohne ihn (realiter) je vorher gesehen zu haben, und kann des Königs geheime Gebete referieren; I, 10) bewegt sich innerhalb dieses Paradigmas.

45 Schiller an Goethe, 24. Dezember 1800; Der Briefwechsel zwischen Schiller und Goethe (wie Anm. 23), S. 892. - Die „romantische Tragödie“ ist kein Sonderfall im dramatischen Werk Schillers; die Wertschätzung des 'romantischen Ritterschauspiels' (an Körner, 21. Januar 1802; NA 31, 90f.) läßt Schiller unmittelbar nach Beendigung der Jungfrau von Orleans mit einem vergleichbaren Projekt, Die Gräfin von Flandern, beginnen. - Daß die Wahl des Untertitels um 1801 vor allem auch eine „verkaufsfördernde Maßnahme“ gewesen sei (Friedrich Schiller: Dramen IV [wie Anm. 27], S. 664), setzt voraus, daß 'romantisch' und 'gothic' in der zeitgenössischen Rezeption unmittelbar gleichgesetzt worden sind, soll hier aber zumindest nicht unerwähnt bleiben.

46 Zum Beispiel über Reimschlüsse (vgl. NA 9, 298; 301 u. a.).
} 
Dialektik von, wie Tieck sagt, Bedeutungsauflösung im reinen „Ton und Klang“ und prägnanter Verbindung der ,ähnlichlautenden Worte“ ergibt. ${ }^{47}$

Die Lyrisierung des dramatischen Sprechens, ${ }^{48}$ in Die Braut von Messina noch sehr viel konsequenter durchgeführt als in der „romantischen Tragödie“, zielt dabei vergleichbar dem Chorkommentar auf Depotenzierung der Illusion. ${ }^{49}$ Schillers Kriegserklärung in der Chor-Vorrede zur Braut von Messina kennt hauptsächlich zwei Waffen gegen den „Naturalism in der Kunst“ (NA 10,11), die bereits im Zusammenhang der seit Ende der 1780er Jahre entstehenden Ritter von Malta (Die Malteser) zum Einsatz gekommen sind: ${ }^{50}$ die 'metrische Sprache' und den 'Chor'. Dabei bleibt die in Schillers dramatischem Hauptwerk vielfältig erprobte Freiheit der Form, die sich als Projekt einer Autonomisierung der Kunst im poetischen Spiel beschreiben läßt, auf das Publikum fixiert; in Schillers antiillusionistischer Dramaturgie halten sich Interesse und Irritation die Waage. ${ }^{51}$ Wie die an den spanischen Formen geschulte metrische Vielfalt der Dramen Tiecks und später Fouqués markiert die Lyrisierung des dramatischen Sprechens den Übergang in eine andere Welt; ${ }^{52}$ der Chor erhält - vergleichbar den epischen Instanzen in Leben und Tod der heiligen Genoveva („Bonifatius“), in Kaiser Octavianus („Romanze“) oder in Fouqués Historie vom edlen Ritter Galmy (der Erzähler) $-^{53}$ die Funktion einer Kontrollinstanz, zum einen als souveräner Kommentator, zum anderen als ins Geschehen involvierter Agitator..$^{54}$

Zum einen leitet sich daraus der gnomische Stil dieser Texte ab, der (so Schiller in Ueber die tragische Kunst), das 'sittliche Gemüt' ,aus der Dienstbarkeit der Sinne zur Selbsttätigkeit" bringen soll (NA 20, 158f.), zum anderen enthält die Chorrede

${ }^{47}$ Ludwig Tieck: Vorrede. In: Minnelieder aus dem schwäbischen Zeitalter, Hildesheim 1966 (reprografischer Nachdruck der Ausgabe Berlin 1803), S. I-XXX, S. XIII; die theoretische Begründung liefert A.[ugust] F.[erdinand] Bernhardi: Sprachlehre, Berlin 1801. - Zu diesem Komplex allgemein vgl. Menninghaus: Unendliche Verdopplung (wie Anm. 10), S. 9-29.

48 Vgl. NA 9, 180f. (Johannas Abschied in Stanzen), NA 9, 268-271 (Johannas innere Unruhe nach der Begegnung mit Lionel; hier wechseln Stanzen, Volksliedstrophe, gereimte und ungereimte jambische Fünfheber); NA 9, 228-231 (die Montgomery-Episode in Trimetern).

49 Vgl. August Klingemann: Ueber Schillers Tragödie: Die Jungfrau von Orleans. 1802, mit einer Nachbemerkung hg. von Gabriella Balassa, Hannover 1997, v. a. S. 19-22.

${ }^{50}$ NA 28, 72 (Schiller an Wilhelm von Humboldt, 5. Oktober 1795).

51 „Der Chor reinigt also das tragische Gedicht, indem er die Reflexion von der Handlung absondert, und eben durch diese Absonderung sie selbst mit poetischer Kraft ausrüstet" (NA 10, 13). Vgl. dazu NA 20, 195 (Vom Erhabenen).

${ }^{52}$ In der Musikalisierung der Darstellung führt Schiller, einer zeitgenössischen Rezension zufolge, Tiecks Metrik-Projekt fort: „Schiller war der erste, welcher den Versuch machte, dem deutschen Schauspiele die Abwechslung der reimlosen Jamben mit gereimten zu geben, welche man vorher nicht einmal in Uebersetzungen Shakespeare's dem Originale nachzubilden versucht hatte. Tieck, von welchem hier nur die Genoveva erwähnt sey, behielt neben den reimlosen Jamben wie Shakespeare auch die Prosa im Dialog bey, und erweiterte von der andern Seite das Gebiet der Reime im Schauspiele, mehr als irgend einer es vor ihm gethan hatte. In der Jungfrau von O. finden wir nun die höchste Freyheit in Rhythmus, Metrum und Reim, und die reinste Wechselbestimmung dieser Formen und des Inhalts des Gedichts“, wobei Rhythmus und Reim als die ,äußere Musik der Rede“ gelten (Johann August Apel. 1802; Schiller und sein Kreis [wie Anm. 25], S. 471f.).

${ }^{53}$ Diese Erzählerfigurationen übernimmt das zeitgenössische Drama aus Shakespeares Henry V. oder Pericles.

54 Über den „doppelten Charakter“ des Chors vgl. Schiller an Körner, 10. März 1803; Briefwechsel zwischen Schiller und Körner (wie Anm. 35), S. 327. 
Widersprüche, die ein Gegengewicht zum rein sinnlichen Interesse auf stofflicher Ebene darstellen - beispielsweise gehen Fürstenkritik und Fürstenlob unmittelbar ineinander über ${ }^{55}$ Nicht der Chor übernimmt die Rolle des Souveräns, sondern das $\mathrm{Pu}-$ blikum / die Leser: Während diese die Vorgänge kennen, die den dramatis personae noch verborgen bleiben (u. a. ist von Isabellas „Verworrenheit“ die Rede; NA 10, 99), kann der Chor weder „fassen“ noch „,deuten“, „/ Wie es so schnell sich erfüllend genaht" (NA 10, 91). Ungeachtet dieser Deutungsunsicherheit behauptet der Chor an anderer Stelle gerade eine Art hermeneutischer Kompetenz, wenn er (in Auseinandersetzung mit der am 'Geschick' inzwischen völlig verzweifelnden Isabella) die beiden sich scheinbar ausschließenden Orakelsprüche mit dem Handlungsverlauf zusammenbringt: Indem die Tochter das Haus vernichtet, rettet sie es, und zwar in der Fortdauer ihrer eigenen Person. Beide Orakel, so der Chor, treffen ein (NA 10, 108).

Wenn schließlich das Finale der Braut von Messina jede Vereindeutigung ablehnt (,Erschüttert steh ich, weiß nicht, ob ich ihn / Bejammern oder preisen soll sein Loos“; NA 10, 125), ${ }^{56}$ wird die Ambivalenz des Chors - vorbereitet durch dessen teils wertfreie, teils unsittliche Positionierung innerhalb des Konflikts ${ }^{57}$ ins Indifferente hin verlängert. Der Text erhält auf diese Weise eine subscriptio, die seinen artifiziellen Charakter unterstreicht. Dieses Theater ist keine moralische Anstalt mehr, sondern Experimentierfeld. Das Spiel der Formen marginalisiert den bearbeiteten Stoff und dessen inhaltliche Deutung; generische Überlegungen (z. B. die Vorläuferschaft zur Schicksalsdramatik Zacharias Werners) spielen eine ebenso untergeordnete Rolle wie thematologische (z. B. die Schuldproblematik). Wie die Metrifizierung des dramatischen Sprechens, so treibt auch die Einführung episierender Elemente die Poetisierung der Poesie voran: „In der neuen Tragödie wird [der Chor, C. S.] zu einem Kunstorgan, er hilft die Poesie hervorbringen. Der neuere Dichter findet den Chor nicht mehr in der Natur, er muß ihn poetisch erschaffen und einführen" (NA 10, 11). Der universalpoetische Entwurf der Romantik, die an der Poetisierung des Lebens arbeitet ${ }^{58}$ erhält so eine dramaturgische Bestätigung. ${ }^{59}$ Für kritische Zeitgenossen jedenfalls steht die Ähnlichkeit der poetischen Projekte in Konzeption und Anwendung außer Frage. Sophie Reimarus schreibt (wenn auch abwertend) über Schillers Braut von Messina:

Ein verzerrtes Wesen bleibt das Ganze wie es zusammengestellt ist, und nach dem Wallenstein hätte ich lieber mit der Maria, und dem Mädchen von Orlean[!] ge-

\footnotetext{
55 „Die fremden Eroberer kommen und gehen, / Wir gehorchen, aber wir bleiben stehen“ vs. „Preis ihr und Ehre, / Die uns dort aufgeht, / Eine glänzende Sonne, / Knieend verehr ich dein herrliches Haupt“" (NA 10, 29).

56 „Schuld“ ist zwar von „Uebel“ (NA 10, 125), inwiefern sie aber die dargestellten Vorgänge tangiert, bleibt offen.

57 Vgl. z. B. die Langeweile des Chors nach Beendigung des Streits zwischen den Brüdern (NA 10, 50).

${ }^{58}$ Ludwig Tieck: Vorrede (wie Anm. 47), S. II.

59 Entgegen Luserke, demzufolge Die Braut von Messina ,ein Stück [ist], das gegen die Literatur um 1800 geschrieben wurde. Klassik bedeutet so verstanden Kritik an der zeitgenössischen Literatur, in erster Linie der Literatur der Spätaufklärung und der Romantiker“ (Friedrich Schiller: Dramen IV [wie Anm. 27], S. 721f.).
} 
schloßen, als mit der Schlegelschen Klicke einer Neuerung nachgejagt, die schwerlich algemein gefallen konnte. Dieser Trieb etwas recht Ungewöhnliches aufzustellen schafft oft Caricaturen; Schiller wird es wohl übelnehmen, daß man ihn mit den Schlegeln zusammenstellt, und es hat ihn doch derselbe Wind angeweht, wie er seine alte und neue Mythologie zusammenstellte, der im Tieck Hunde und Katzen, und Tisch und Bäume reden läßt. ${ }^{60}$

Vergleichbar wird die hier polemisch ineinsgesetzte Dramatik vor allem durch ihren elitären Charakter. Die Ansprüche an die Zuschauer / Leser sind hoch; so erfordert es eine adäquate Rezeption der Jungfrau von Orleans, jenen „Indifferenzpunkt des Ideellen und Sinnlichen“ (NA 10, 12) herzustellen, der Schiller zufolge dem Chor eignet. Mit anderen Worten ist das Publikum in das Geschehen sowohl involviert (insofern es die vorgestellte 'wunderbare Wirklichkeit' akzeptiert), als die hermeneutischen Herausforderungen von Thema und Textstruktur auch eine beobachtende, also unbeteiligte Perspektive voraussetzen. In diesem Sinne bewegt sich der Betrachter zwischen Affekt und Reflexion. ${ }^{61}$ Die Vieldeutigkeit des Geschehens wertet seine Position auf, macht den Text aber zugleich angreifbar, und zwar von seiten einer Kritik, die den heterogenen Charakter des Stücks (oder einzelner Figuren) der scheinbar defizitären Komposition und nicht der tatsächlich defizitären eigenen Lektüre anlastet. ${ }^{62}$ Der Leser ist, wie Novalis sagt, eine ,höhere Instanz, die die Sache von der niedern Instanz schon vorgearbeitet erhält" ${ }^{63}$ ohne den der Text aber unvollständig (oder besser: unvollendet) bleibt. Die klassische Identifikationsdramaturgie dagegen hält das Publikum unmündig. Schillers Projektskizze Die Prinzessin von Zelle beispielsweise entwirft den Plan einer einheitlichen, in allen Teilen motivierten, 'prägnanten' Handlung, vermittels derer die „Erwartung in hohem Grade gespannt und bis ans Ende immer in Athem gehalten“ wird. Die Konzentration auf einen „einzigen Punkt“ läßt keine Deutungsspielräume zu. ${ }^{64}$ Vergleichbares gilt auch für Maria Stuart, der bereits das zeitgenössische Urteil eine „,vollkommne Einheit des Interesse“ bescheinigt. $^{65}$

${ }^{60}$ An Sulpiz Boisserée, 2. September 1803 (Franz Schulz: Ein Urteil über die Braut von Messina. Aus ungedruckten Briefen von Sophie Reimarus an Sulpiz Boisserée. In: Euphorion 12 [1905], S. 592599; S. 598).

${ }^{61}$ Zur Intellektualisierung der Rezeption um 1800 vgl. Jochen Schulte-Sasse: Das Konzept bürgerlichliterarischer Öffentlichkeit und die historischen Gründe seines Zerfalls. In: Aufklärung und literarische Öffentlichkeit, hg. von Christa Bürger, Peter Bürger und J. S.-S., Frankfurt/M. 1980, S. 83115; S. 108-110.

62 So z. B. Christian Otto an Jean Paul, 20. November 1801 (Jean Pauls Briefwechsel mit seinem Freunde Christian Otto. Vierter Band, Berlin 1833 [Repr. Berlin-New York 1978], S. 54f.). - Zum Stellenwert von Vieldeutigkeit in den ästhetischen Diskussionen des 18. Jahrhunderts vgl. Gerhard Kurz: Vieldeutigkeit. Überlegungen zu einem literaturwissenschaftlichen Paradigma. In: Vom Umgang mit Literatur und Literaturgeschichte. Positionen und Perspektiven nach der 'Theoriedebatte', hg. von Lutz Danneberg und Friedrich Vollhardt, Stuttgart 1992, S. 315-333.

${ }^{63}$ Novalis: Schriften. Zweite, nach den Handschriften ergänzte, erweiterte und verbesserte Auflage. Zweiter Band: Das philosophische Werk I, hg. von Richard Samuel, Stuttgart 1965, S. 470.

${ }^{64}$ NA 12, 331. Bemerkenswerterweise hat Schiller diesen Plan nicht ausgeführt.

${ }^{65}$ Schiller im Urtheile seiner Zeitgenossen (wie Anm. 19), S. 122. - Beispielsweise bleibt der Zuschauer/Leser über das Verstellungsspiel Mortimers ebensowenig im unklaren wie über die ethische Positionierung Marias (Mortimer erklärt sich sowohl für Maria als auch für Elisabeth, die 'Authentizität' des erstgenannten Bekenntnisses aber belegt der sich unmittelbar anschließende Monolog in 
Die hermeneutische Dimension der Jungfrau von Orleans dagegen leitet sich bereits aus dem verhandelten Gegenstand (Stoff) ab; das Deutungsproblem stellt sich sowohl auf dramaturgischer als auch auf thematischer Ebene. Je nach Überlieferungszusammenhang ergeben sich aus der Frage nach der 'Echtheit' oder 'Authentizität' der Figuren, die (vergleichbar dem in Arnims und Fouqués Nationaltheater behandelten Waldemar-Komplex $)^{66}$ für die auktoriale Beglaubigung der jeweiligen Daseinsansprüche relevant ist, unterschiedliche dramaturgische Herausforderungen: Der wissentliche Betrug Warbecks ermöglicht eine Spiel-im-Spiel-Struktur, in der 'öffentliche Maske' und 'wahres Ich' zunächst gegeneinander ausgespielt, durch Warbecks zunehmendem Selbstbetrug dann aber immer konturloser werden. Weil die Ambivalenz der Figur damit stets präsent ist, ${ }^{67}$ besteht nur dann keinerlei Deutungsbedarf, wenn der historische Kontext bekannt ist. ${ }^{68}$ Die „,volle tragische Größe“ des Demetrius dagegen, von der Schiller in einem Brief an Körner spricht, ${ }^{69}$ resultiert aus dem Spannungsverhältnis von authentischem Anspruch und historischem Fehlurteil. Solange Demetrius von der Rechtmäßigkeit seines Begehrens überzeugt ist, hat er Erfolg, sobald er sich als Opfer der Intrige Marinas erkennt, muß er scheitern. Im Unterschied zu Demetrius weiß das Publikum, wiewohl in die Entscheidungsfindung des polnischen Reichstags direkt involviert, ${ }^{70}$ von den ersten Szenen an um Marinas Inszenierung (,Er glaub an sich, so glaubt ihm auch die Welt“; NA 11, 29); Deutungsprobleme ergeben sich hier - im Unterschied zu Warbeck - nicht. ${ }^{71}$

Aus dieser Perspektive läßt sich Schillers ,romantische Tragödie“ Die Jungfrau von Orleans als ein „Gegenstück“ zu Demetrius beschreiben:"2 Die anfängliche Inszenierung einer romantischen Gegenwelt mit ihren 'schauerhaften Mären, 'wundersamen Klängen' und 'gespenstischen Weibern', in die auch christliche Metaphorik bruchlos integriert wird, bereitet Johannas wunderbare, im Wortsinn überirdische Initiation in die neue Rolle einer Erretterin Frankreichs vor. Die zu allen 'realen'

II, 6; die Exposition des ersten Akts dient hauptsächlich der Rehabilitation Marias, einer den historischen Zeugnissen zufolge anstößigen Figur).

${ }^{66}$ Ludwig Achim von Arnim: Der echte und der falsche Waldemar. In: ders.: Schaubühne. Vierter Theil. Neue Ausgabe, Berlin 1857 (Repr. Hildesheim-Zürich-New York 1982), S. 1-238; Fouqué behandelt die Frage in einer Abhandlung (Ueber den sogenannten falschen Waldemar, Berlin 1811) und in einem vaterländischen Schauspiel (Waldemar der Pilger, Markgraf von Brandenburg. Ein Trauerspiel in fünf Aufzügen. In: ders.: Vaterländische Schauspiele, Berlin 1811, S. 1-132).

67 Schiller zufolge ist es erforderlich, ,daß sich Warbek immer in seiner doppelten Person zugleich darstelle“ (NA 12, 199).

${ }^{68}$ Darauf baut Schillers Plan zufolge der erste Akt des Stücks: „Kurz das Hauptintereße ruht jezt noch auf der Maske, welche durch sich selbst interessiert. Hier kann die Täuschung so weit gehen als möglich [...]. Dieses dauert bis zum Ende des Acts, wo der Zuschauer wegen der wahren Beschaffenheit und Bewandtniß anfangen darf in Unruhen zu kommen" (NA 12, 177f.).

69 Schiller an Körner, 25. April 1805; Briefwechsel zwischen Schiller und Körner (wie Anm. 35), S. 343.

${ }^{70}$ So der ausführliche Nebentext zu Beginn der 'Reichstagsfassung': „Alsdann stellt er sich so, daß er einen großen Theil der Versammlung und des Publikums, von welchem angenommen wird daß es im Reichstag mit sitze, im Auge behält [...]“ (NA 11, 8).

71 Vgl. dazu Helmut Pfotenhauer: Um 1800. Konfigurationen der Literatur, Kunstliteratur und Ästhetik, Tübingen 1991, S. 192.

72 Schiller an Körner, 25. April 1805; Briefwechsel zwischen Schiller und Körner (wie Anm. 35), S. 343. 
('irdischen') Ansinnen, Vorwürfen und Fremdbeschreibungen schweigende Figur erhält - mit dem Helm als kriegerischem insignium (NA 9, 176) - eine Stimme, die sie ,,in Begeisterung“(NA 9, 177) in die politische Diskussion eingreifen läßt. Unter der Voraussetzung der damit nicht mehr hinterfragbaren Eigengesetzlichkeit dieser Realität gibt es an Johannas (göttlicher) Berufung keinen Zweifel. Die Musikalisierung der Darstellung durch den metrischen Wechsel in die Stanzenform soll diesen Eindruck noch verstärken - mit sprachlichen Mitteln erreicht der Text damit die Wirkmächtigkeit der Oper, deren Vorteil Schiller zufolge darin besteht, das inhaltliche Moment zurückzudrängen. ${ }^{73}$

Gleichzeitig geht die historische Johanna in den Prolog ein. Aus dem Verhältnis von überlieferter Figur und dramatis persona resultiert die Schillers Bearbeitung leitende Frage, ob Johannas Verhalten auf eine ,schwere Irrung der Natur“ (NA 9, 169) zurückzuführen sei, wie Thibaut befürchtet, oder ob sich darin, mit Raimond, „was Höhres“ offenbare (NA 9, 170), ob sich also mit Johannas „unbegreiflich[em] Glück“ ein „,eigen Grauen“ (Thibaut) verbinde oder 'Überschwang' (Raimond; NA 9, 172). Irritierende Momente installiert bereits die Exposition: Thibauts Traum bestätigt zunächst Johannas Glaubwürdigkeit, indem die historische Figur zum Bild der Himmelskönigin Maria erstarrt, der sich der gesamte Erdkreis unterwirft. Die in diesem Bild implizierte göttliche Legitimation Johannas aber ignoriert der 'realistische', mithin beschränkte Blick Thibauts, wenn er daraus Johannas „tiefen Fall“ (NA 9, 171) ableitet. Die hermeneutische Kompetenz der dramatis persona, ein Relikt der emblematischen Strukturen repräsentativer Dramatik, wird hier zitiert und (zumindest vom Finale her) widerlegt. Der Dramenverlauf allerdings gibt Thibauts pessimistischer Prognose fürs erste recht. Das starre Bild wird zu einem „blinde[n] Schrecken“ der Phantasie (NA 9, 223), Johannas Furcht vor dem eigenen Vater (NA 9 , 287) erhärtet Thibauts frühen superbia-Vorbehalt (,Und büßen will ichs mit der strengsten Buße, / Daß ich mich eitel über euch erhob!“; NA 9, 285) und leitet schließlich ihren Fall am Ende des vierten Aufzugs ein. Eine brauchbare, d. h. glaubwürdige Deutung der Krönungssituation aber wird man von Thibaut nicht erwarten dürfen. Von vornherein hält er an seiner frühen Verurteilung Johannas fest: In IV, 8 betritt er „schwarz gekleidet“ die Bühne, mit den Worten „Sahst du mein unglückselig Kind?“ (NA 9, 280); die Rückführung des Wunders auf „des Teufels Kunst“ (NA 9, 287) stellt demzufolge keine verallgemeinerbare Aussage dar. Wie bereits im Prolog oder in der Beurteilung Johannas durch Talbot (NA 9, 223) erscheint die Figur nicht als das, was sie ist, sondern als das, was in sie hineingelegt wird.

\footnotetext{
${ }^{73}$ Schiller an Goethe, 29. Dezember 1797: „Die Oper stimmt durch die Macht der Musik und durch eine freiere harmonische Reizung der Sinnlichkeit das Gemüt zu einer schönern Empfängnis, hier ist wirklich auch im Pathos selbst ein freieres Spiel, weil die Musik es begleitet, und das Wunderbare, welches hier einmal geduldet wird, müßte notwendig gegen den Stoff gleichgültiger machen“ (Der Briefwechsel zwischen Schiller und Goethe [wie Anm. 23], S. 529). - In die Pläne zu Rosamund oder die Braut der Hölle gehen dergleichen Überlegungen ein (NA 12, 259-268). - Die Nähe der Jungfrau von Orleans zur Oper unterstreichen zudem musikalische Szenenschlüsse (NA 9, 255) und 'Theaterzauber' (der schwarze Ritter versinkt mit Blitz und Donner; NA 9, 262).
} 
Zudem sind Handeln und Selbstdeutung der Hauptfigur nicht frei von Widerspruch. Zwar bestätigt das Finale die bereits im Prolog formulierte Vorwegnahme des weiteren Werdegangs (,Johanna geht und nimmer kehrt sie wieder!“; NA 9, 180), schon Johannas Aussagen über ihre Berufung aber, die für die Bewertung des Handelns insgesamt zentral sind, divergieren: Die im Abschiedsmonolog beschriebene kommunikative Situation insinuiert einen Gesprächspartner, hinter dem sich der Geist Gottes verbirgt (,Er sprach zu mir aus dieses Baumes Zweigen [...]“; NA 9, 181). Am Hof des Königs berichtet Johanna dagegen von ihrer Berufung durch die in Gestalt einer Schäferin auftretende Gottesmutter; jetzt also erging nicht mehr „,des Geistes Ruf“ an Johanna (NA 9, 180), sondern der Ruf Marias (,,...] sie sprach zu mir [...]“; NA 9, 207). Auch unter Vorannahme einer überrealen Sphäre wird die Erwartung an eine stringente 'Geschichte' Johannas (im Sinne ihrer 'göttlichen' Beglaubigung) dadurch nachhaltig irritiert.

Wenn schließlich die Ambivalenz der Figur im Schweigen gerinnt, Johanna zu einer Statue versteinert, die jede Antwort verweigern muß, bringt die Frage nach Johannas Verantwortlichkeit das Legitimationsproblem auf den Punkt. Der Sieg der irdischen Neigung (Lionel) über die himmlische Pflicht, der den himmlischen Sieg über Karls irdische Feinde abwertet und Johannas Schuld besiegelt, ist ihr nämlich dann nicht ernsthaft anzulasten, wenn sich darin, wie es wiederholt heißt, ein Johanna von vornherein bestimmtes „Schicksal“ (NA 9, 254) erfüllt. Ihre Stummheit am Ende des vierten Aufzugs bestätigt eben nicht jene oxymorale Struktur, die man der „Dramaturgie des Schweigens“ um 1800 gemeinhin zuordnet und die sich mit Goethes Symbolbegriff aus der unmittelbaren, sprachlosen Evidenz der Anschauung ergibt. ${ }^{74}$ In der Jungfrau von Orleans wird die Zweideutigkeit der Rede nicht etwa durch ein beredtes Schweigen ersetzt, in dem alles (Notwendige) gesagt ist; die inszenierte Stille potenziert den Interpretationsbedarf des Worts vielmehr dadurch, daß dieses Schweigen Zuschauer / Leser und dramatis personae gleichermaßen ratlos macht: ${ }^{75}$ „Wir sind verwirrt“, so - stellvertretend - der Erzbischof (NA 9, 302). Zudem wird Johannas in der Einsamkeit der Wälder neu gewonnene Selbstgewißheit („Doch in der Öde lernt ich mich erkennen“; NA 9, 297) umgehend durch die Erinnerung an Lionel beunruhigt (,Kein Gott erscheint [...], der Himmel ist verschlossen“; NA 9, 301), die seherische Gabe, die einen olympischen, göttlichen Blick ermöglicht (,,[m]it meinem Blick wollt ich die Schlacht regieren!“‘; NA 9, 309), ${ }^{76}$ führt geradewegs in eine schwere Glaubenskrise („Gott! Gott! So sehr wirst du mich nicht verlassen!“; NA 9, 310). Am Ende ist es dennoch die (schuldbeladene?) Johanna, die

\footnotetext{
${ }^{74}$ Vgl. dazu Christiaan L. Hart Nibbrig: Rhetorik des Schweigens. Versuch über den Schatten literarischer Rede, Frankfurt/M. 1981, S. 51-86.

75 'Der Himmel' scheint an dieser Stelle Thibauts Schuldspruch zu bestätigen: ,Wer wagts, sie eine Schuldige zu nennen? Ein heftiger Donnerschlag, alle stehen entsetzt“ (NA 9, 289). Bezieht man allerdings den kulturhistorisch belegten Funktionswandel des Gewissens im Gewitter um 1800 ein, stellt sich Johannas Ruhe als Ausdruck einer inneren Sicherheit, mithin eines 'guten Gewissens' dar, vgl. Heinz D. Kittsteiner: Die Entstehung des modernen Gewissens, Frankfurt/M. 1995, S. 87f.

${ }^{76}$ Die Blindheit des irdischen Blicks steht dazu in Kontrast: ,Soldat. Alles ist / In Staub vermengt. Ich kann nichts unterscheiden. / Johanna. Hätt er mein Auge oder stünd ich oben, / Das Kleinste nicht entginge meinem Blick!“‘ (NA 9, 309).
} 
- der Voraussage zum Trotz (NA 9, 254) - das finale Treffen gegen die Engländer besteht $(\mathrm{V}, 12)$.

Die Klärung des hermeneutischen Dilemmas bleibt letztendlich auktorialer Steuerung überantwortet, ohne daß damit die auf absoluter Klarheit ${ }^{77}$ sowie emotionaler Abhängigkeit ${ }^{78}$ basierende Bevormundungsdramatik des 18. Jahrhunderts reaktiviert würde: „Der die Verwirrung sandte, wird sie lösen!“ (NA 9, 298). Die oben beschriebene Aufwertung des Beobachters geht mit einer Stärkung der Autor-Position einher; weil der Text nicht mehr kausallinear organisiert ist, sondern labyrinthisch, und weil die poetische Fiktion weniger leicht durchschaubar ist als die reale, ist jede Orientierung auf Vermittlung angewiesen. Sich dieser zu bedienen, gehört zu den neuen Anforderungen an die Rezeption. Während beispielsweise Tiecks auf den ersten Blick unüberschaubares Universaldrama Kaiser Octavianus durch ein umfassendes, auf allen Ebenen installiertes Verweissystem zusammengehalten wird, ${ }^{79}$ macht Die Jungfrau von Orleans unentwegt auf die Rollenhaftigkeit der Figur aufmerksam, die, als eine Art alter Maria eingeführt und doch von Maria berufen, fortlaufend zwischen göttlicher Funktion (Johanna, die Schlächterin) und irdischer Begrenzung (Johanna, der Mensch), zwischen poetischer und historischer Existenz, changiert. Der kontrastreiche schnelle Szenenwechsel am Ausgang des zweiten und dritten Akts ist strukturelles Pendant dieser fortschreitenden hermeneutischen Verunsicherung auf inhaltlicher Ebene und zugleich Garant für deren Lösung. ${ }^{80}$ Weil auf diese Weise jede „vernünftige Illusion“81 verhindert wird, die das Theater der Aufklärung ebenso wie das klassische Drama einfordern, erhält der Zuschauer / Leser jene Kompetenz, die ihn zu einem „Autor in der 2t Potenz ${ }^{\text {“82 }}$ macht - nicht zuletzt ihrer episodischen Ordnung wegen führt Tieck Schillers Johanna von Orleans auf die

77 „Für den Zuschauer muß alles klar sein. [...] er weiß alles was vorgeht, alles was vorgegangen ist [...]“ (Das Theater des Herrn Diderot. Aus dem Französischen übersetzt von Gotthold Ephraim Lessing, mit Anmerkungen und Nachwort von Klaus-Detlef Müller, Stuttgart 1986, S. 334). - Entsprechend heißt es in der Vorbemerkung zu Fiesko: ,[...] die Natur des Dramas duldet den Finger des Ohngefährs oder der unmittelbaren Vorsehung nicht" (NA 4, 9).

78 Schon der frühe Schiller reflektiert auf dieses Prinzip: „Heilig und feierlich war immer der stille der grose Augenblick in dem Schauspielhaus, wo [...] ich des Zuschauers Seele am Zügel führe, und nach meinem Gefallen, einem Ball gleich dem Himmel oder der Hölle zuwerfen kann“ (NA 4, 272; Erinnerung an das Publikum). Die klassische Poetologie setzt diese Überlegung fort, vgl. dazu Die Prinzessin von Zelle, Maria Stuart.

79 Vgl. dazu C. S.: Das dramatische Werk Fouqués (wie Anm. 22), Kap. 2.2 (Welttheater).

${ }^{80}$ In der Montgomery-Episode beispielsweise agiert Johanna als Werkzeug Gottes (,Nicht mein Geschlecht beschwöre! Nenne mich nicht Weib“; NA 9, 229), im darauffolgenden Monolog als Mensch (,In Mitleid schmilzt die Seele und die Hand erbebt“; NA 9, 231) etc. - Zudem erhält der epische Zeitverlauf der Handlung durch die Fünfaktigkeit der dramatischen Komposition eine gewisse 'Geschlossenheit' (vgl. Gerhard Storz: Der Dichter Friedrich Schiller, Stuttgart 1959, v. a. S. 351-353)

81 Tieck: Der gestiefelte Kater. Kindermärchen in drei Akten. Mit Zwischenspielen, einem Prologe und Epiloge, hg. von Helmut Kreuzer, durchgesehene und bibliographisch ergänzte Ausgabe 1984, Stuttgart 1996, S. 11.

${ }^{82}$ So Friedrich Schlegel über den Kritiker (KA 18, 106). 
eigene dramatische Produktion zurück, in erster Linie auf Leben und Tod der heiligen Genoveva, ${ }^{83}$ den „Prototyp des romantischen Dramas schlechthin“ “. ${ }^{84}$

Ein anderes Ordnungsschema entwerfen Schillers Skizzen Die Polizey, die nach Merciers Tableau de Paris (1782/83) die Darstellung städtischer Totalität auf ein alle Bereiche beherrschendes und überwachendes System hin organisieren: die Polizei. Poetologisch perspektiviert, reagiert dieses auktoriale Prinzip auf die neue Ganzheitskonzeption und die daraus resultierende episodische Vielfalt, indem der Autor den Text dadurch handhabbar macht und eine in dessen Struktur angelegte 'Zerstreuung' der Rezeption verhindert. Die Polizei ist, mit Schiller, ein „leitender / Faden“, der „die Mannichfaltigkeit der Begebenheiten und die Menge der Figuren“ so verknüpft, daß das Publikum „nicht verwirrt wird“. Bezeichnenderweise bleibt das Projekt unausgeführt. Das mag an der ,ungeheure[n] Maße von Handlung“ (NA 12, 91) gelegen haben, die zu bewältigen war; allerdings gelangen auch die Versuche, den Stoff durch thematische (Kleinstadt) sowie generische (Lustspiel) Verlegung in den Griff zu bekommen, oder die Neuordnung beider Pläne in Die Kinder des Hauses über den Projektstatus nicht hinaus (NA 12, 429-432). Wie auch immer: In Schillers Dramen geht es ebenso wie in der (auch theoretisch) ambitionierten Dramatik der Zeit um die Problematik der Darstellung von Totalität. Eine weitere Lösung erprobt Die Braut von Messina, die neben vermittelnden Elementen wie der aus der Rhetorik übertragenen repetitio-Struktur ${ }^{85}$ den Chor als kohärenzstiftende Instanz einsetzt („Der Chor hielt das Ganze trefflich zusammen") ${ }^{86}$.

Die dramaturgische Herausforderung besteht demzufolge darin, das nicht mehr auf strenge Chronologie und Folge ausgerichtete Szenarium überschaubar zu halten; die (zumindest partielle) Simultaneität der Darstellung setzt einen aus den Gegebenheiten des Textes selbst dazu befähigten souveränen Beobachter voraus. Die Poetologie der Klassizität dagegen, so Wilhelm von Humboldt, operiert mit der Kategorie der Zeit und nicht des Raumes. Das „Streben nach einem Ganzen der Kunstform“, das nicht zuletzt die formalen Mängel der frühen Dramen auszugleichen beabsichtige, verwirkliche sich vorzugsweise in der klassischen Dramatik Schillers:

Denn auch sie sammelt ihre ganze Wirkung auf Einen[!] Endpunkt, verfolgt mehr eine Linie, als sie sich auf eine Fläche verbreitet, und steht, wie auch der Gedanke, in engerem Bunde mit der Zeit, als mit dem mehr der Anschauung zusagenden Raume. ${ }^{87}$

83 „Vielleicht haben Sie die Genoveva später gelesen, wie manches, was durch sie gewissermaßen entstanden ist; denn Maria Stuart, die Jungfrau von Orleans, vollends die Wernerschen Thorheiten und das Heer jener katholischen Dichter, die nicht wissen was sie wollen, sind alle später" (Tieck an Solger, 30. Januar 1817; Karl Wilhelm Ferdinand Solger: Nachgelassene Schriften und Briefwechsel, hg. von Ludwig Tieck und Friedrich von Raumer, I, Heidelberg 1973 [Faksimiledruck nach der Ausgabe von 1826, mit einem Nachwort hg. von Herbert Anton], S. 501).

${ }^{84}$ Gerhard Kluge: Das romantische Drama. In: Handbuch des deutschen Dramas, hg. von Walter Hinck, Düsseldorf 1980, S. 186-199; S. 192.

85 Beispiele dafür sind der unterschiedlich perspektivierte Bericht über Beatrices vermeintlichen 'Fehltritt' (NA 10, 57f., 59, 70f., 77, 89f.) oder die wiederholte Schilderung der beiden Orakelträume (65f., 107f.).

86 Schiller an Körner, 28. März 1803; Briefwechsel zwischen Schiller und Körner (wie Anm. 35), S. 328. 
Schiller selbst hatte dieses hier formulierte Klassizitätsideal in Auseinandersetzung mit Wielands Kritik an Die Künstler ausgebildet und seiner Rezension der Gedichte Bürgers unterlegt, ${ }^{88} \mathrm{zu}$ beachten ist aber, daß Schiller, zumindest im Briefwechsel mit Körner, die Kategorie der „Üppigkeit“ in die Klassizitäts-Debatte einbringt. Er hält Wielands Forderung nach Einheit der Form die Forderung nach größtmöglicher Anschaulichkeit entgegen, die gerade durch die „natürliche Fortschreitung“ des immerselben Gedankens in „,neuen Formen“ bewirkt werde ${ }^{89}$ In den sog. KalliasBriefen an Körner lehnt Schiller es ab, „Schönheit“ über gängige Charakteristika wie „Zweckmäßigkeit, Ordnung, Proportion, Vollkommenheit ${ }^{“ 90} \mathrm{zu}$ definieren; zeittypisch $^{91}$ illustriert er seine Vorstellung von Vollendung am Beispiel der 'Landschaft'. Diese sei dann ,„schön komponiert“,

wenn alle einzelne Partien, aus denen sie besteht, so ineinanderspielen, daß jede sich selbst ihre Grenze setzt, und das Ganze also das Resultat von der Freiheit des Einzelnen ist. Alles in einer Landschaft soll auf das Ganze bezogen sein, und alles Einzelne soll doch nur unter seiner eigenen Regel zu stehen, seinem eigenen Willen zu folgen scheinen.

Die „Harmonie des Ganzen“ setzt voraus, daß jedes Teil „aus innerer Freiheit sich gerade die Einschränkung vorschreibt, die das andere braucht, um seine Freiheit $\mathrm{zu}$ äußern“".92 Diese Aufwertung des einzelnen Teils behauptet dessen Selbständigkeit, die dann wiederum den Gesamtzusammenhang aller Teile betreffen soll. Ins Poetologische gewendet, unterläuft die ästhetische Rechtfertigung des Teils die Dramentheorie Schillers, indem eine davon abgeleitete Dramaturgie die Gattungsgrenze zum Epos hin verschiebt. ${ }^{93}$ Die mit Ausnahme von Maria Stuart panoramatische, partiell episodische Präsentationsform von Schillers Dramatik zieht dann auch die massive Kritik Körners auf sich, der beispielsweise die Wallenstein-Trilogie, dieses ,für un-

${ }^{87}$ Humboldt: Ueber Schiller und den Gang seiner Geistesentwicklung (wie Anm. 12), S. 524, 495, $523 \mathrm{f}$.

${ }^{88}$ Walter Hinderer: Schiller und Bürger. Die ästhetische Kontroverse als Paradigma. In: Jahrbuch des Freien Deutschen Hochstifts 1986, S. 130-154, v. a. S. 140-146.

${ }^{89}$ Schiller an Körner, 25. Februar 1789; Briefwechsel zwischen Schiller und Körner (wie Anm. 35), S. 104. Vgl. auch Körner an Schiller, 12. April 1789; ebda., S. 115.

90 Schiller an Körner, 23. Februar 1793; Briefwechsel zwischen Schiller und Körner (wie Anm. 35), S. 185.

91 Zur seit 1750 sich verändernden Ordnungsvorstellung (begründet mit Herder zunächst historisch, dann mit den Romantikern poetisch) vgl. Michael Gamper: „Die Verfassung sei republikanisch“. Verhandlungen über Ordnung und Unordnung in den Kunstdebatten des 18. Jahrhunderts. In: Zeitschrift für deutsche Philologie 119 (1999), S. 189-215 (zusammengeführt werden die ShakespeareRezeption, die Theorie der Gartenkunst und die politische Theorie des 18. Jahrhunderts). Zur Bestimmung der Neuzeit aus der Verbindung von Ordnung und Kontingenz vgl. Aleida Assmann: Let it be. Kontingenz und Ordnung in Schicksalsvorstellungen bei Chaucer, Boethius und Shakespeare. In: Kontingenz, hg. von Gerhart v. Graevenitz und Odo Marquard, München 1998, S. 225-244, v.a. S. 242.

${ }_{92}$ Schiller an Körner, 23. Februar 1793; Briefwechsel zwischen Schiller und Körner (wie Anm. 35), S. 187.

93 In der „Selbständigkeit der Teile“ sieht Schiller bekanntlich einen „Hauptcharakter des epischen Gedichtes“ (an Goethe, 21. April 1797; Der Briefwechsel zwischen Schiller und Goethe [wie Anm. 23], S. 375). 
sere Zimmer" allzu große „Gemälde“, in vorliegender Form ablehnt. ${ }^{94}$ An anderer Stelle wird deutlich, von welchen 'barbarischen' Formen Körner die dramatische Produktion Schillers fernhalten möchte: Als gleichsam abschreckendes Beispiel für alles „Chaotische“ gilt ihm Tiecks Kaiser Octavianus, das er als 'Produkt der Mode' bezeichnet. ${ }^{95}$ - Nur eine Generation später wird die Historiographin einer Geschichte der Moden, Caroline de la Motte Fouqué, Schillers Jungfrau von Orleans zum Inbegriff und Vorbild romantischer Dramatik erklären:

Wohl kann man sagen, der Vorhang einer neuen Welt ward aufgezogen. Wenn der spätern[!] romantischen Schule ohnstreitig das Verdienst zugeschrieben werden muß, die Richtung nach dem Idealen ausgebildet zu haben, so darf es nicht vergessen werden, daß die Jungfrau von Orleans das erste vollständige Kunstwerk war, welches diese Richtung allgemein gab. ${ }^{96}$

\section{III. „Es mangelt ihm die Einheit der Handlung“. Panoramatik in Wilhelm Tell}

Eine in der Zeitschrift Isis im März 1805 veröffentlichte Kritik der Erstausgabe des Wilhelm Tell setzt bei der Struktur des Textes an; moniert wird in erster Linie die Zusammenhanglosigkeit der Teile, d. h. die Episodizität der Darstellung: Wilhelm Tell sei

zu viel und zu wenig Shakespearisch, jenes in der Form, dieses im inneren Gehalt. Ein Hauptfehler [...] liegt im Plan des Ganzen; es mangelt ihm die Einheit der Handlung, welche kein dramatischer Dichter, auch der größte nicht, ungestraft verletzen darf. ${ }^{97}$

Zudem bestehe „die Hälfte von Schillers Tell aus einer Zusammenflechtung mehrerer, wenig zusammenhängender Episoden. Sie könnten wegfallen, ohne daß das Ganze in Rücksicht des Thema's verlöre" ".98 An Wilhelm Tell werden demzufolge Maßstäbe angelegt, die mit dessen Dramaturgie kollidieren und die auch für Schillers Dramentheorie selbstverständlich sind. Zum einen zielt die (klassische) Forderung nach Einheit auf eine Idealisierung der Darstellung, nicht auf epische Breite; zum anderen aber unterläuft der Text die Strategien einer auf affektive Wirkung angelegten Illusionsdramatik: „Die durch das ganze Gemälde zerstreuten Strahlen, nirgends zu einem Brennpunkt aufgefangen, glänzen, ohne erwärmen zu können. “99 Diese in

94 Körner an Schiller, 16. Januar 1800; Briefwechsel zwischen Schiller und Körner (wie Anm. 35), S. 298.

95 Körner an Schiller, 27. Juli 1804; Briefwechsel zwischen Schiller und Körner (wie Anm. 35), S. 337.

96 Caroline de la Motte Fouqué: Geschichte der Moden, vom Jahre 1785 bis 1829 . Als Beytrag zur Geschichte der Zeit, hg. und mit einem Nachwort versehen von Dorothea Böck, Berlin 1987, S. 67.

97 Schiller im Urtheile seiner Zeitgenossen (wie Anm. 19), S. 430 [Wilhelm Tell von Schiller, beurtheilt von einem Schweizer; Isis. März 1805].

98 Schiller im Urtheile seiner Zeitgenossen (wie Anm. 19), S. 431. - Positiver formuliert heißt es in der Zeitung für die elegante Welt (13. Oktober 1804; ebda., S. 393): „Ich finde eine Menge schöner Theile und kein Ganzes“.

99 Schiller im Urtheile seiner Zeitgenossen (wie Anm. 19), S. 430 [Isis. März 1805]. 
Isis formulierte Diskrepanz von Rezeptionserwartung und Handlungsverlauf verdeutlicht gerade die dramaturgische Positionierung der titelgebenden Hauptfigur. Tell nämlich interessiere den Leser nur kurz, bald verliere er sich ,wie eine Nebenperson, im Gedränge andrer Erscheinungen“"

So steht des Lesers Aufmerksamkeit beständig getheilt, seine Theilnahme immer unschlüssig zwischen mehreren anziehenden Gegenständen - oft erwärmend, und eben so oft erkaltend, läßt das Ganze zuletzt nur einen verworrenen Eindruck, eine laue Empfindung zurück. ${ }^{100}$

'Verworrener Eindruck' und 'zerstreute Strahlen' - im zeitgenössischen Verständnis dieser Terminologie wird die Darstellung, weil sie auf die ,gehörige Ordnung“ verzichte, ,unwirksam oder auch unwirklich“; sie vernachlässige das Beabsichtigte oder

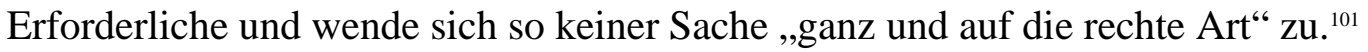

Ein weiterer fundamentaler Vorbehalt gegen Wilhelm Tell reformuliert das seit Bodmers Verdikt gepflegte Vorurteil, die Verarbeitung historischer Stoffe könne für das zeitgenössische Publikum (aufgrund unzureichender Identifikationsangebote) unmöglich interessant sein. ${ }^{102}$ Schillers Vorrede zu Fiesko bestätigt diese Einschätzung, indem sie in Anlehnung an Lessing eine Rettung des Genres über die Privatisierung der historisch-politischen Thematik versucht (NA 4, 9f.). Demnach widerspricht das 'historische Drama' einer auf Geschlossenheit angelegten Ganzheitsästhetik,

weil der menschliche Geist in einem dramatischen Kunstwerke hoher Art eine beschränkte Handlung umfassen will, das Leben und der Tod eines Mannes, oder eine ausgedehnte politische Begebenheit, aber keine dramatische Einheit der Handlung gewährt. ${ }^{103}$

Darüber hinaus führen die Göttingischen gelehrten Anzeigen die vor diesem Hintergrund beschriebenen 'Fehler' der Dramatisierung auf die historische Genauigkeit der Stoffbehandlung zurück ${ }^{104}$ - tatsächlich korrespondiert die Zweiteilung in Tellund Schweizerhandlung ${ }^{105}$ der Zweiteilung der Überlieferung zum einen in die

${ }^{100}$ Schiller im Urtheile seiner Zeitgenossen (wie Anm. 19), S. 430.

101 Wörterbuch der Deutschen Sprache (wie Anm. 40), S. 852; so auch Johann Christoph Adelung: Grammatisch=kritisches Wörterbuch der Hochdeutschen Mundart, mit beständiger Vergleichung der übrigen Mundarten, besonders aber der Oberdeutschen. Zweyte vermehrte und verbesserte Ausgabe, Leipzig 1801 (2. Repr. Hildesheim-Zürich-New York 1990), Sp. 1692f.

102 Art. Politisches Trauerspiel. In: Johann Georg Sulzer: Allgemeine Theorie der schönen Künste in einzelnen, nach alphabetischer Ordnung der Kunstwörter aufeinanderfolgenden Artikeln abgehandelt. III, Hildesheim-Zürich-New York 1994 (2., unveränderter Nachdruck der Ausgabe Leipzig 1793), S. 710-716.

${ }^{103}$ Schiller im Urtheile seiner Zeitgenossen (wie Anm. 19), S. 400f. (Göttingische gelehrte Anzeigen. 24. November 1804).

104 „Hätte sich der Dichter mehr an die Eingebungen seines Genie's, als an die Historie gehalten, er würde ohne Zweifel etwas Vollendetes geleistet haben. Möchte er doch die geschichtliche Treue verletzt haben - man erwartete von ihm keinen dramatischen Auszug aus Müllers Geschichte der Eidsgenossen, sondern Poesie“ (Schiller im Urtheile seiner Zeitgenossen [wie Anm. 19], S. 432 [Isis. März 1805]).

105 „Man sollte beinahe glauben, Schiller habe zwei durch ihren Stoff mit einander verwandte Schauspiele in ein Einziges zusammenzuschmelzen versucht" (Schiller im Urtheile seiner Zeitgenossen 
Sagentradition (hier gilt Tell als Befreier und Gründer der Eidgenossenschaft), zum anderen in die historiographische Tradition, die Tells Geschichte der allgemeinen Geschichte des Befreiungskampfs subsumiert. ${ }^{106}$ Weil Wilhelm Tell aber eine Synthese der beiden Überlieferungsstränge versucht und nicht etwa den historiographischen bevorzugt, ${ }^{107}$ wird der hier artikulierte Realismus- oder (mit Schillers Chor-Vorrede) Naturalismus-Vorwurf durch die Dramaturgie des Textes widerlegt. Historische Genauigkeit und poetische Wahrheit stehen in einem komplementären Verhältnis; daraus ergeben sich Aufschlüsse über die Verbindung von Dramenstruktur und historiographischem Anspruch, der in das poetische Projekt integriert ist und so eine ganze eigene (nämlich literarische) Qualität erhält. Hatte der frühe Schiller dem Dichter noch weitreichende Kompetenzen über die Geschichte eingeräumt (einmal mehr erweist er sich damit als Schüler Lessings), ${ }^{108}$ so fordert der Historiker Schiller ein sowohl extensives als auch kritisches Quellenstudium, das es schließlich erlaubt, die Einzelheiten der Überlieferung zu einem sinnvollen Ganzen zu verknüpfen. ${ }^{109}$ Im kreativen Vermögen der Darstellung von Zusammenhängen sind Historiker und Dichter vergleichbar; sie zeichnen sich beide, wie Schiller sagt, durch eine „schöpferische[ ] Hand“ (NA 17, 363) aus. Während aber die Anerkennung des poetischen Einfallsreichtums eine Verpflichtung zur idealisierenden Verkürzung enthält (,,[...] der Dichter male für Ameisenaugen, und bringe auch die andere Hälfte in unsern Gesichtskreis verkleinert herüber; er bereite uns von der Harmonie des Kleinen auf die Harmonie des Grossen; von der Symmetrie des Theils auf die Symmetrie des Ganzen"), ${ }^{110}$ bedingt die genaue historische Recherche ${ }^{111}$ eine neue literarische Präsentationsform, die der ,,dem Ort und der Zeit nach ganz zerstreut auseinander" ${ }^{\prime 12}$ liegenden Handlung annähernd gerecht wird. Die Ausweitung der dramatischen Handlung ins Episodische, die eine Einteilung in Haupt- und Nebenhandlung (en) erschwert, läßt sich daraus ebenso erklären wie die lose Verknüpfung der Einzelszenen, deren Zusammenhalt den olympischen Betrachter voraussetzt, ${ }^{113}$ oder die

[wie Anm. 19], S. 431).

106 Gert Ueding: Wilhelm Tell. In: Interpretationen. Schillers Dramen, hg. von Walter Hinderer, Stuttgart 1992, S. 385-422.

107 Beispielsweise fehlt in Müllers Schweizergeschichte, der historischen Wahrscheinlichkeit wegen, die Apfelschußszene (Friedrich Schiller: Wilhelm Tell. Erläuterungen und Dokumente, hg. von Josef Schmidt, durchgesehene, bibliographisch ergänzte Ausgabe, Stuttgart 1979, S. 60).

108 NA 4, 9 (Vorbemerkung zu Fiesko). Vgl. z. B. Lessing: Werke, hg. von Herbert G. Göpfert. Fünfter Band: Literaturkritik. Poetik und Philologie, München 1973, S. 207.

109 „So würde denn unsre Weltgeschichte nie etwas anders als ein Aggregat von Bruchstücken werden, und nie den Nahmen einer Wissenschaft verdienen. Jezt also kommt ihr der philosophische Verstand zu Hülfe, und, indem er diese Bruchstücke durch künstliche Bindungsglieder verkettet, erhebt er das Aggregat zum System, zu einem vernunftmäßig zusammenhängenden Ganzen“ (NA 17, 373; Was heisst und zu welchem Ende studiert man Universalgeschichte?).

110 NA 20, 82f. (Ueber das gegenwärtige teutsche Theater).

111 Zum Beispiel verlangt Schiller in einem Brief an Cotta, 16.(?) März 1802 (NA 31, 116), eine ,genaue Special Charte von dem Waldstättensee und den umliegenden Cantons“.

112 An Körner, 9. September 1802; Briefwechsel zwischen Schiller und Körner (wie Anm. 35), S. 321.

113 Als Beleg genüge der Szenenwechsel des ersten und zweiten Aufzugs (NA 10, 131-192): Naturidyll und Wetterwende, Rettung Baumgartens (Tell) - Gertrud und Stauffacher (die Notwendigkeit einer Verschwörung) - die Fron, Stauffacher und Tell - die Geschichte Melchthals (Stauffacher, Walther Fürst und Melchthal verbünden sich) - Haltung des Adels (Attinghausen, Rudenz) - Der 
numerische Ausweitung des Personals, die eine sozial differenzierte Perspektivierung auf das historische Ereignis ermöglicht. ${ }^{14}$

Geschichte wird dabei nicht um ihrer selbst willen zum Vorwurf dramatischer Darstellung; vielmehr bildet das historische Ereignis die Geschichte der Menschheit symbolisch ab: Die sog. Schweizerhandlung verallgemeinert die sog. Tell-Handlung und ist zugleich Symbol für den Geschichtsverlauf insgesamt, den die in Wilhelm Tell dramatisierte Geschichtsphilosophie als Restitution der ursprünglichen Einheit in der utopisch-idyllischen Schlußapotheose beschreibt. ${ }^{115}$ Historischer Realismus im Drama geht so mit einer Deutung der Überlieferung einher, in der, prototypisch für das frührealistische Geschichtsdrama der ersten Hälfte des 19. Jahrhunderts insgesamt, der geschichtsmächtige Einzelne, das große Individuum zunehmend marginalisiert wird. Selbst das Wunderbare ist in diese Form realistischer Darstellung integrierbar, garantiert deren Märchenhaftigkeit Novalis zufolge doch ein höheres Maß an (historischer) Authentizität. ${ }^{116}$ Es geht, wie Schiller am 4. April 1797 an Goethe schreibt, um die Rekonstruktion der 'eigentlichen Geschichte' jenseits des historischen Faktums, ${ }^{117}$ und wenn die Vorrede zur Braut von Messina der „wahre[n] Kunst [...] etwas reelles und objektives“ zuschreibt, so daß sie ,zugleich ganz ideell und doch im tiefsten Sinne reell“" (NA 10, 9) sei, nähert sich Schiller damit der polemischen Neusetzung des Begriffs 'Realismus' in Friedrich Schlegels Gespräch über die Poesie, das das Ideale als das Reale in höherer Potenz gelten läßt (KA 2, 315). In Konsequenz dessen wird die idealisierende Perspektivierung unbrauchbar. Es vertritt nicht mehr das Detail den Gesamtzusammenhang, sondern unterschiedliche Details stellen einen Zusammenhang her, der dann wiederum auf eine höhere Deutungsebene verweist.

Für die an Schiller anschließende Dramengeschichte gilt dagegen: Je grundlegender die szenische Herstellung von Totalität, desto mehr tritt die symbolische Qualität des Dargestellten in den Hintergrund. In praktischer Hinsicht radikalisieren Texte wie Fouqués Herrmann, Grabbes Napoleon oder Büchners Danton das in der Dramaturgie von Wilhelm Tell vorbereitete Konzept realistischer Geschichtsdramatik; in theoretischer Hinsicht wird es hauptsächlich durch Solger und Tieck weitergetrieben, deren Überlegungen zur historiographischen Dramatik die Anforderung an Detailgenauigkeit und Faktentreue mit einer literarischen Gestaltung vereinen, die das Tatsächliche zum Möglichen hin erweitert. ${ }^{118}$

Rütli-Schwur.

114 Zentrales Thema der Einzelgeschichten ist das die politischen Verhältnisse je eigens illustrierende persönliche Leid (z. B. Baumgartens, Bertas oder Melchthals).

115 Ueding: Wilhelm Tell (wie Anm. 106), S. 421f.

116 Novalis: Schriften. Zweite, nach den Handschriften ergänzte, erweiterte und verbesserte Auflage. Erster Band: Das dichterische Werk, hg. von Paul Kluckhohn und Richard Samuel, Stuttgart 1960, S. 259.

117 Der Briefwechsel zwischen Schiller und Goethe (wie Anm. 23), S. $363 f$.

118 Solger: Nachgelassene Schriften und Briefwechsel, hg. von Ludwig Tieck und Friedrich von Raumer, II, Heidelberg 1973 (Faksimiledruck nach der Ausgabe von 1826, mit einem Nachwort hg. von Herbert Anton), v. a. S. 579-626 (Beurtheilung der Vorlesungen über dramatische Kunst und Literatur); Tieck: Die Piccolomini. Wallenstein's Tod (wie Anm. 4); ders.: Vorrede. In: Fr.[iedrich] von Üchtritz: Alexander und Darius. Trauerspiel, Berlin 1827, S. III-XVI. 
Ein von der Dramaturgie des frührealistischen Geschichtsdramas unterschiedenes 'Realismus'-Verständnis leitet dagegen Schillers Bühnenbearbeitungen, ${ }^{119}$ die sich an den Kriterien zum einen der bühnentechnischen Vereinfachung, zum anderen der Glaubwürdigkeit des Dargestellten orientieren. Das zeigt beispielsweise die Veränderung des Finales von Goethes Egmont, dessen (wenn auch traumhafter) Triumph im Untergang durch die relative Offenheit in der Beurteilung von Egmonts politischen Leistungen ersetzt wird (Kriegsmusik substituiert die Siegessymphonie und deutet auf diese Weise die Unabgeschlossenheit des Freiheitskampfs an; NA 13, 72). Schillers 'konsequente' Bearbeitung macht damit die in struktureller Hinsicht 'romantischen' Tendenzen von Goethes Egmont rückgängig. ${ }^{20}$ Sie ist Kriterien der Theatralität unterworfen, die auf 'Kompaktheit' ausgerichtet sind (ansonsten hätte Schiller weder auf die Liedeinlagen noch auf das opernhafte Finale verzichten dürfen): Kürzungen, Raffungen, Szenenumstellungen und partielle Hinzufügungen dienen der Vereinfachung des Handlungszusammenhangs, dessen Bestandteile stärker motiviert und so nicht nur übersichtlicher gestaltet, sondern auch psychologisch plausibilisiert werden. Einzelne Handlungselemente entfallen dabei entweder ganz (wie die Margarete-Handlung) oder werden stark verkürzt (wie die Clärchen-Handlung); das episodische Mosaik der Vorlage, zusammengehalten durch streng parallele Szenenordnung, ${ }^{121}$ wird zugunsten einer finalen, ausschnitthaft-konzentrierten und absoluten Disposition ${ }^{122}$ aufgehoben. Mit anderen Worten zielt Schillers Egmont auf Illusion, vermittelnde Elemente (Lieder, Allegorien) haben hier keinen Platz. ${ }^{123}$

Der experimentelle Charakter von Schillers Dramaturgie dagegen ist mit der auf Gattungsreinheit zielenden klassizistischen Poetologie ${ }^{124}$ nicht vereinbar, eher schon mit Friedrich Schlegels dezidiert 'modernem' Gattungsbegriff, der die „Methode“ des „Experimentiren[s]“ und der Kombinatorik propagiert: „Wer nach dieser Methode verfährt, der darf sich die kühnsten Versuche erlauben“. ${ }^{125}$ Der romantischen Ganzheitskonzeption zufolge ermöglicht allererst eine 'Zerstreuung' der Aufmerk-

119 In diesem Sinne „fehlt“ der „Sinn für die epische Totalität des Lebens, die sich in Goethes Dichtung ausformt“, nicht „dem Dramatiker Schiller“ (NA 13, 304), sondern dem Bühnenpraktiker.

${ }^{120}$ Man könnte (nach Friedrich Schlegel) auch sagen: Wilhelm Meisters Bedeutung für den zeitgenössischen Roman entspricht Egmonts Bedeutung für das zeitgenössische Drama; dem Universalroman korrespondiert eine Universaldramatik (vgl. Steffen Martus: Sinn und Form in Goethes Egmont. In: Goethe-Jahrbuch 1998, S. 45-61, v.a. S. 47).

121 Der erste, zweite, vierte und fünfte Aufzug beginnt mit einer Straßenszene und wechselt dann zu Palast und Bürgerhaus (I), Egmonts Wohnung (II), Palast (IV) und zwischen Gefängnis und Bürgerhaus (V); im dritten Aufzug fehlt lediglich die Straßenszene (er wechselt von Palast zu Bürgerhaus), vgl. Johann Wolfgang Goethe: Italien und Weimar. 1786-1790. I, hg. von Norbert Miller und Hartmut Reinhardt (ders.: Sämtliche Werke nach Epochen seines Schaffens. Münchner Ausgabe, hg. von Karl Richter. Band 3.1), München-Wien 1990, S. 246-329 (Egmont).

${ }^{122}$ Zur Terminologie vgl. Manfred Pfister: Das Drama. Theorie und Analyse, durchgesehene und ergänzte Auflage, München 1988, S. 104-106.

123 Damit folgt die Bearbeitung der Egmont-Rezension von 1788, in der Schiller die episierenden Tendenzen des Textes (NA 22, 200) und Verstöße gegen die Regeln des Illusionstheaters (ebda., 208f.) kritisiert hatte.

124 Zusammenfassend Sven Gesse: 'Genera mixta'. Studien zur Poetik der Gattungsmischung zwischen Aufklärung und Klassik/Romantik, Würzburg 1997, S. 136.

125 KA 12, 102 (Transzendentalphilosophie. Jena 1800-1801); vgl. dazu Gesse, 'Genera mixta' (wie Anm. 124), S. 207. 
samkeit (also die Ablenkung von Inhalt und Handlungsverlauf) deren 'Bündelung' auf die Form; die Poetisierung der Welt und ihrer 'willkürlichen' Erscheinungen ist auf eine 'zerstreute' Darstellung geradezu angewiesen. Die poetische Leistung besteht darin, die Vereinigung des Heterogenen zu erzeugen, die Leistung der Rezeption, die „schöne und wohlgefällige Symmetrie“ zu bemerken, in die sich - Tieck zufolge - ,ein wildes und unregelmässiges Aeussere“ (wie dasjenige der Dramen Shakespeares) bei genauerem Hinsehen ordnet. ${ }^{126}$ Diese Darstellung faßt Totalität ins Mosaik einzelner Ereignisse, die idealisierende Deduktion hat als Beurteilungsmaßstab ausgedient. In der Dorfszene des Demetrius beispielsweise soll, so Schillers Szenar, gerade die „Totalität von Motiven [...] auf eine prägnante Art das Getrennte coexistent machen" (NA 11, 206), die vermeintliche Formlosigkeit ist Ausdruck eines neuen Formbewußtseins. ${ }^{127}$ In diesem Sinne hat Schillers Dramaturgie das poetische Projekt der Romantik mit vorbereitet; darin besteht ihre Modernität.

${ }^{126}$ Das Buch über Shakespeare. Handschriftliche Aufzeichnungen von Ludwig Tieck. Aus seinem Nachlaß hg. von Henry Lüdeke, Halle/S. 1920, S. 299 f.

127 In dieser Hinsicht kann Schiller nicht gegen die Romantik ausgespielt werden (so Terence James Reed: Schiller und die Weimarer Klassik. In: Schiller-Handbuch [wie Anm. 27], S. 216-232;

S. 224); ungenau sind auch die Ausführungen Gampers über die Ordnungsvorstellung der Frühromantik, die „Ordnung nicht in jeder Form abgelehnt“ habe (Gamper: „Die Verfassung sei republikanisch“ [wie Anm. 91], S. 213). 